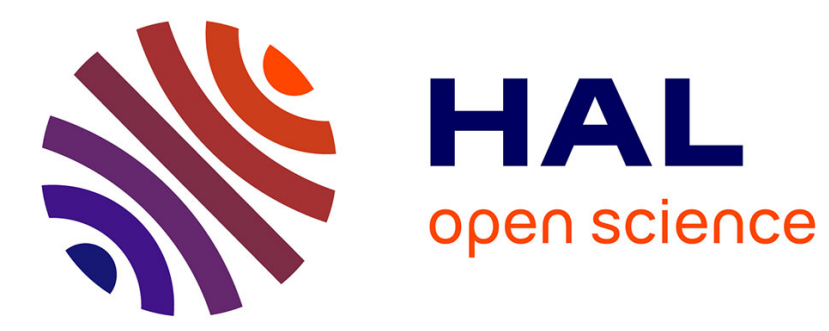

\title{
Pilot study: Rapamycin in advanced hepatocellular carcinoma
}

\author{
Maximilian Schöniger-Hekele, Christian Müller
}

\section{To cite this version:}

Maximilian Schöniger-Hekele, Christian Müller. Pilot study: Rapamycin in advanced hepatocellular carcinoma. Alimentary Pharmacology and Therapeutics, 2010, 32 (6), pp.763. 10.1111/j.13652036.2010.04404.x . hal-00555326

\section{HAL Id: hal-00555326 https://hal.science/hal-00555326}

Submitted on 13 Jan 2011

HAL is a multi-disciplinary open access archive for the deposit and dissemination of scientific research documents, whether they are published or not. The documents may come from teaching and research institutions in France or abroad, or from public or private research centers.
L'archive ouverte pluridisciplinaire HAL, est destinée au dépôt et à la diffusion de documents scientifiques de niveau recherche, publiés ou non, émanant des établissements d'enseignement et de recherche français ou étrangers, des laboratoires publics ou privés. 


\begin{tabular}{l}
\hline Alimentary Pharmacology \\
\hline \& Therapeutics \\
\hline
\end{tabular}

\section{Pilot study: Rapamycin in advanced hepatocellular carcinoma}

\begin{tabular}{|c|c|}
\hline Journal: & Alimentary Pharmacology \& Therapeutics \\
\hline Manuscript ID: & APT-0285-2010.R2 \\
\hline Wiley - Manuscript type: & Original Scientific Paper \\
\hline $\begin{array}{r}\text { Date Submitted by the } \\
\text { Author: }\end{array}$ & 15-Jun-2010 \\
\hline Complete List of Authors: & $\begin{array}{l}\text { Schöniger-Hekele, Maximilian; Medical University of Vienna, Klinik } \\
\text { Innere Medizin III, Gastroenterology and Hepatology } \\
\text { Müller, Christian; Medical University of Vienna, Klinik Innere } \\
\text { Medizin III, Gastroenterology and Hepatology }\end{array}$ \\
\hline Keywords: & $\begin{array}{l}\text { Hepatocellular carcinoma < Hepatology, Liver < Organ-based, } \\
\text { Cancer - chemotherapy < Topics, Oncology - chemotherapy }< \\
\text { Topics }\end{array}$ \\
\hline
\end{tabular}


1

2

3

4

\section{Pilot study: Rapamycin in advanced hepatocellular carcinoma}

Maximilian Schöniger-Hekele, Christian Müller

Klinik Innere Medizin III, Abteilung für Gastroenterologie und Hepatologie, Medizinische Universität Wien

Key words: Hepatocellular carcinoma (HCC), rapamycin

\section{Correspondence addresses:}

Prof. Dr. Christian Müller MD. and

Prof. Dr. Maximilian Schöniger-Hekele MD.,

Department of Internal Medicine III

Division of Gastroenterology and Hepatology

Medical University of Vienna

Währinger Gürtel 18 - 20,

A-1090 Wien,

Vienna, Austria

Tel.: $\quad$ +43 (1) 40400-4741

Fax.: $\quad+43$ (1) 40400-4735

e-mail: christian.j.mueller@meduniwien.ac.at

e-mail: maximilian.schoeniger-hekele@meduniwien.ac.at
Formatted: Left: $70.85 \mathrm{pt}$, Right: 70.85 pt, Top: 70.85 pt, Bottom: $56.7 \mathrm{pt}$, Width: $595.3 \mathrm{pt}$, Height: $841.9 \mathrm{pt}$, Header distance from edge: $35.4 \mathrm{pt}$, Footer distance from edge: $35.4 \mathrm{pt}$

Deleted: Effects of the mTOR inhibitor rapamycin in patients with hepatocellular carcinoma: a phase lla trial

\{




\author{
Abstract \\ Introduction: The PI3K/Akt/mTOR signal pathway is involved in hepatocarcinogenesis. \\ Rapamycin (= Sirolimus), a specific mTOR inhibitor, leads to $\mathrm{G}(1)$ arrest of many malignant \\ cell lines, and currently analogs of rapamycin are being investigated as a cancer \\ chemotherapeutic adjuvant. \\ Aim: To study the toxicity and tolerability of rapamycin therapy in patients with advanced \\ hepatocellular carcinoma (HCC). \\ Methods: Between June 2005 and February 2007 patients with advanced HCC, not eligible \\ for any established therapy, were included in the study. \\ Results: 18 patients (f/m: 5/13) with compensated liver cirrhosis (Child $A n=11$, Child $B n=5$, \\ Child $\mathrm{Cn}=2$ ) and histologically proven HCC were included in this study. According to the BCLC \\ staging system most of the patients enrolled had an advanced HCC: BCLC stage B: $n=2, B C L C$ \\ stage $C: n=14, B C L C$ stage $D: n=2$. Overall, therapy with rapamycin was well tolerated. Most \\ common toxicities were thrombocytopenia and anemia. We did not observe any partial or \\ complete tumor response. At 3 months two patients had stable disease, at 6 months all \\ patients had progressed. The median overall survival was 5.27 months, median time to \\ progression was 3 months. Conclusion: Rapamycin is well tolerated in patients with \\ advanced HCC but only minimally effective.
}


Hepatocellular carcinoma (HCC) is a tumor of high prevalence worldwide and shows an increasing incidence in the western world. More than $90 \%$ of all Hepatocellular carcinoma develop in a cirrhotic liver. Known major risk factors for the development of liver cirrhosis and Hepatocellular carcinoma are chronic hepatitis B or hepatitis C, alcoholic liver cirrhosis or genetic hemochromatosis. The incidence rate of HCC in patients with underlying liver cirrhosis is approximately 3 to $4 \%[1]$.

Therapeutic options depend on the stage of underlying liver cirrhosis, on the number and diameter of tumor nodules and the performance status; these factors are combined in the BCLC [2] staging system. Liver transplantation and liver resection are potentially curative treatment options which were offered patients in BCLC stage A (Child-Pugh stage A, 1 nodule $<5 \mathrm{~cm}$ or 3 nodules $<3 \mathrm{~cm}$ ). Also local ablative treatment options (PEI, RFA) are potentially curative treatment options which were used in this group of patients. However, many HCC patients present with a $\mathrm{BCLC}$ stage $\mathrm{B}$ (Child-Pugh stage $\mathrm{A}$ or $\mathrm{B}$, multinodular) or $\mathrm{BCLC}$ stage $\mathrm{C}$ (Child-Pugh stage A or B, multinodular, portal invasion, N1, M1; without potential curative treatment options). Transarterial chemoembolisation (TACE) for BCLC stage B or treatment with the vascular endothelial growth factor inhibitor Sorafenib for BCLC stage $\mathrm{C}$ are offered to these groups of patients and have been shown to prolong survival [3 4567 8]. Sorafenib, a multikinase inhibitor, represents a breakthrough in the management of advanced hepatocellular carcinoma and shows a significantly better survival compared to placebo. Nevertheless, there is need for new therapeutic agents for those patients 
A recently discussed new treatment option is Rapamycin (= Sirolimus), a specific mTOR inhibitor („,mammalian target of rapamycin“). Rapamycin is inhibiting the PI3K/Akt/mTOR signal pathway which is involved in multiple cellular functions including proliferation, differentiation, tumorgenesis, and apoptosis. Rapamycin, the naturally occurring inhibitor of mTOR and a number of recently developed rapamycin analogues inhibit the growth of cell lines derived from multiple tumor types in vitro, and tumor models in vivo., This specific mTOR inhibitor could lead to G(1) arrest of many malignant cell lines, and currently analogs of rapamycin are being investigated as a cancer chemotherapeutic adjuvant [9 1011$]$. Rapamycin, isolated from Streptomyces hygroscopicus, is a Macrolid-antibiotic with antibacteriel, antifungal and immunosuppressive effects [12 1314 14] and can inhibit mTOR through association with its intracellular receptor FKBP12. The FKBP12-rapamycin complex binds directly to the FKBP12-Rapamycin Binding (FRB) domain of mTOR. The inhibition of mTOR by Rapamycin causes a dephosphorylation and inactivation of some ribosomal proteins and leads to a reduction of synthesis of components of the translation process [15 16]. This is followed by an arrest of the G1-phase of cell cycle which causes immunosupression but also antitumoral effects.

Proteins regulating the mammalian target of rapamycin (mTOR) are overexpressed or mutated in cancer. Results from clinical trials indicate that rapamycin and its analogues may be useful for the treatment of subsets of certain types of cancer [17 18]. Therefore, in this pilot study we studied the toxicity and tolerability of rapamycin in patients with liver cirrhosis and hepatocellular carcinoma. 


\section{METHODS}

\section{PATIENTS}

A total of 18 patients were included into the study between June 2005 and February 2007.

All patients were recruited at the Department of Gastroenterology and Hepatology at the Medical University of Vienna. Most of our patients were in Child B, only two were in Child C stage. Liver cirrhosis and its complications were managed according to state of the art protocols. The demographic data and baseline clinical characteristics are given in Table 1. Liver cirrhosis was diagnosed either by histology or by the typical combination of laboratory tests, clinical and gastroscopic findings and typical signs of liver cirrhosis in CT or ultrasound. Diagnosis of hepatocellular carcinoma was done according to the criteria of EASL [19] and AASLD [20].

Patients with histologically confirmed HCC were eligible if they were 19-85 years of age and were no candidates for liver transplantation, tumor resection, a local ablative therapy (kryotherapy, ethanol instillation, radio frequency ablation) or chemoembolization (TACE). One patient was switched due to progression of the HCC from TACE to Rapamycin. To be eligible for the study the estimated life expectancy had to be more than 3 months. Tumors had to be measurable objectively with CT-scan.

DEFINITION OF TUMOR PROGRESSION 
Tumor progression was judged during the study by comparing tumor diameters during follow up examinations against the measurements obtained at baseline. We used the RECIST

[21 22] and EASL [19] response criteria for evaluation of progression free survival

Deleted: 19

\section{FOLLOW UP}

Routine multislice $\mathrm{CT}$ and ultrasound were performed every three months until death of the patient. Physical examination, serum chemistry, blood cell counts and AFP determinations and Rapamycin plasma levels were done monthly.

\section{TREATMENT MODALITIES}

Rapamycin was administered orally twice daily. The target plasma level was 4 to $8 \mathrm{ng} / \mathrm{ml}$. The planned duration of the study was 6 months. Toxicity assessments were based on reports of adverse events and results of scheduled physical examinations, vital sign measurements and clinical laboratory tests.

\section{STATISTICAL ANALYSIS}

$\mathrm{Chi}^{2}$ test was used to compare proportions and Mann Whitney $\mathrm{U}$ tests to compare median values between groups. Survival times and progression free survival were estimated using the Kaplan-Meier method and the differences were tested with the log-rank test. Analysis was performed with Statistica (StatSoft, Inc. (2004). STATISTICA (data analysis software system), version 6. www.statsoft.com). 
Results

\section{PATIENT CHARACTERISTICS}

18 patients (female: 5 , male: 13 ) with compensated liver cirrhosis (Child $A n=11$, Child $B n=$

5, Child $C n=2$ ) and histologically proven HCC ( $G 1 n=1, G 2 n=14, G 3 n=3$ ) were included in this study. (Table 1)

According to the BCLC staging system most of the patients enrolled had advanced hepatocellular carcinoma: BCLC stage $B: n=2, B C L C$ stage $C: n=14, B C L C$ stage $D: n=2$.

\section{TREATMENT TOXICITY AND TOLERABILITY}

Overall, therapy with rapamycin was well tolerated. We did not observe severe infectious complications. Only 2 spontaneous bacterial peritonitis (SBP) were seen in the 18 patients. Most common laboratory abnormalities were thrombocytopenia and anemia, most often already present at baseline. Neither dose reduction nor termination of treatment was necessary due to severe toxicity.

\section{TUMOR RESPONSE}

We did not observe any partial or complete tumor response. At 3 months two patients had stable disease, at 6 months all patients had progressed.

\section{TIME TO PROGRESSION}

The median time to progression was 3.0 months. (Figure 2) The shortest time to progression was 1.2 months, the longest time to progression was 6.7 months. 
SURVIVAL

The median overall survival was 5.27 months. 6 patients died before the first assessment of tumor progression at 3 months, 5 further patients between the first CT assessment at 3 months and the end of the study at 6 months. 7 patients lived longer than 6 months. However, 3 of those died within one month after end of the study due to progression of disease. The remaining 4 patients, all having progressive disease, were switched to other treatments ( 3 patients to Sandostatin LAR, 1 patient to Sorafenib). They lived for 12, 16, 19 and 28 months respectively. 


\section{Discussion}

In this pilot study 18 patients with compensated liver cirrhosis and histologically proven advanced HCC were treated with Rapamycin, a specific mTOR inhibitor. At 3 months two patients had stable disease, at 6 months all patients had progressed. Our results showed that Rapamycin was well tolerated but was only minimally effective in patients with liver cirrhosis and advanced stage hepatocellular carcinoma.

Although all our patients had liver cirrhosis treatment with Rapamycin resulted in few side effects. No dose reduction due to intolerable side effects was necessary even in patients with Child B liver cirrhosis. We observed only two cases of SBP which were successfully treated with antibiotics despite continuous treatment with Rapamycin. No clear connection to Rapamycin treatment was evident in those patients. In general, in patients with liver cirrhosis and advanced HCC Rapamycin was well tolerated.

We treated our patients between 2005 and 2007 before Sorafenib was registered for treatment of HCC. At present Sorafenib is recommended in patients with advanced HCC and any new treatment should be evaluated against that standard. Sorafenib, a drug which has been proven to prolong survival of patients with advanced HCC in the SHARP trial [6], did not induce complete response in a single patient and only $2 \%$ of all patients had a partial pt, English U.S. response. We saw a similar picture: although we did not observe any partial or complete tumor response at 3 months two patients had stable disease. In the SHARP trial the median time to radiologic progression was only 5.5 months in the sorafenib group. Similarly, under 
Rapamycin treatment all patients had progressed at 6.7 months, the median time to progression was 3.0 months. In general, the limited tumor response and the progression of tumor size do not indicate ineffectiveness of the treatment with Rapamycin, there is considerable discussion whether the EASL and RECIST criteria used to document tumor progression are the best tools to judge the effectiveness of an anti-tumor drug. Focusing on objective tumor shrinkage does not take into account the possibility of other potential beneficial effects of a drug on survival. Median overall survival time was 10.7 months in the sorafenib group in the SHARP trial but only 5.27 months in our patients treated with Rapamycin. Our one year survival rate was $22 \%$. The expected one year survival rate of patients with BCLC stage $\mathrm{C}$ without therapy according to BCLC staging classification would have been $29 \%$ [2] which is not different from our patients actively treated with Rapamycin. However, $97 \%$ of the patients with advanced hepatocellular carcinoma included in the Formatted: Endnote Reference, pont: 12 pt, Comp

Deleted: 2 SHARP trial were rated as Child stage $A$ at baseline, reflecting a well-preserved liver function. On the other hand $38.9 \%$ of our patients treated with Rapamycin were classified as Child stages B or C. Therefore patients included in our trial had worse baseline characteristics and were not directly comparable to the patients included in the SHARP trial. Therefore the effectiveness of Rapamycin can only be evaluated in comparison to a placebo group. New, randomized controlled studies are needed to investigate the effectiveness of Rapamycin or other mTOR inhibitors in patients with hepatocellular carcinoma.

Rapamycin provokes antineoplastic and immunosuppressive effects. Organ transplant recipients treated with mTOR inhibitors have a reduced incidence of de novo posttransplant malignancies. Therefore, the use of Rapamycin in recipients with a high cancer risk like older patients, recipients with a personal history of cancer or high familial cancer risk, could be claimed. Immunosuppressive therapy after liver transplantation might contribute to 
1

2

3

4

5

6

7

8

9

10

11

12

13

recurrence and metastasis of hepatocellular carcinoma. mTOR inhibitors as immunosuppressive agents are an excellent treatment alternative in that situation with data showing an excellent survival and disease free intervals in those patients [23 24 25]. A recently published study based on the Scientific Registry of Transplant Recipients (SRTR) including 2,491 adult recipients of isolated liver transplantation for HCC and 12,167 for nonHCC diagnoses revealed that sirolimus based immunosuppression compared to calcineurin inhibitors has unique posttransplant effects on patients with HCC that lead to improved survival ${ }^{26}$.

The primary usage of mTOR inhibitors as an anti tumor agent in patients with a malignancy but without organ transplantation is controversially discussed [27]. However, recent studies show that the mTOR pathway has an important role in the pathogenesis of HCC. Villanueva et al. demonstrated that an aberrant mTOR signaling was present in half of the cases [17].

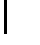
The authors showed that the blockage of mTOR signaling with Rapamycin in vitro and in xenograft models decelerated tumor growth and increased survival. These findings are the rationale for targeting the mTOR pathway in clinical trials in patients with HCC.

In summary, Rapamycin is well tolerated in patients with advanced hepatocellular carcinoma but only minimally effective.

\section{STATEMENT OF INTERESTS:}

No financial support was received for this study. 
Figure 1

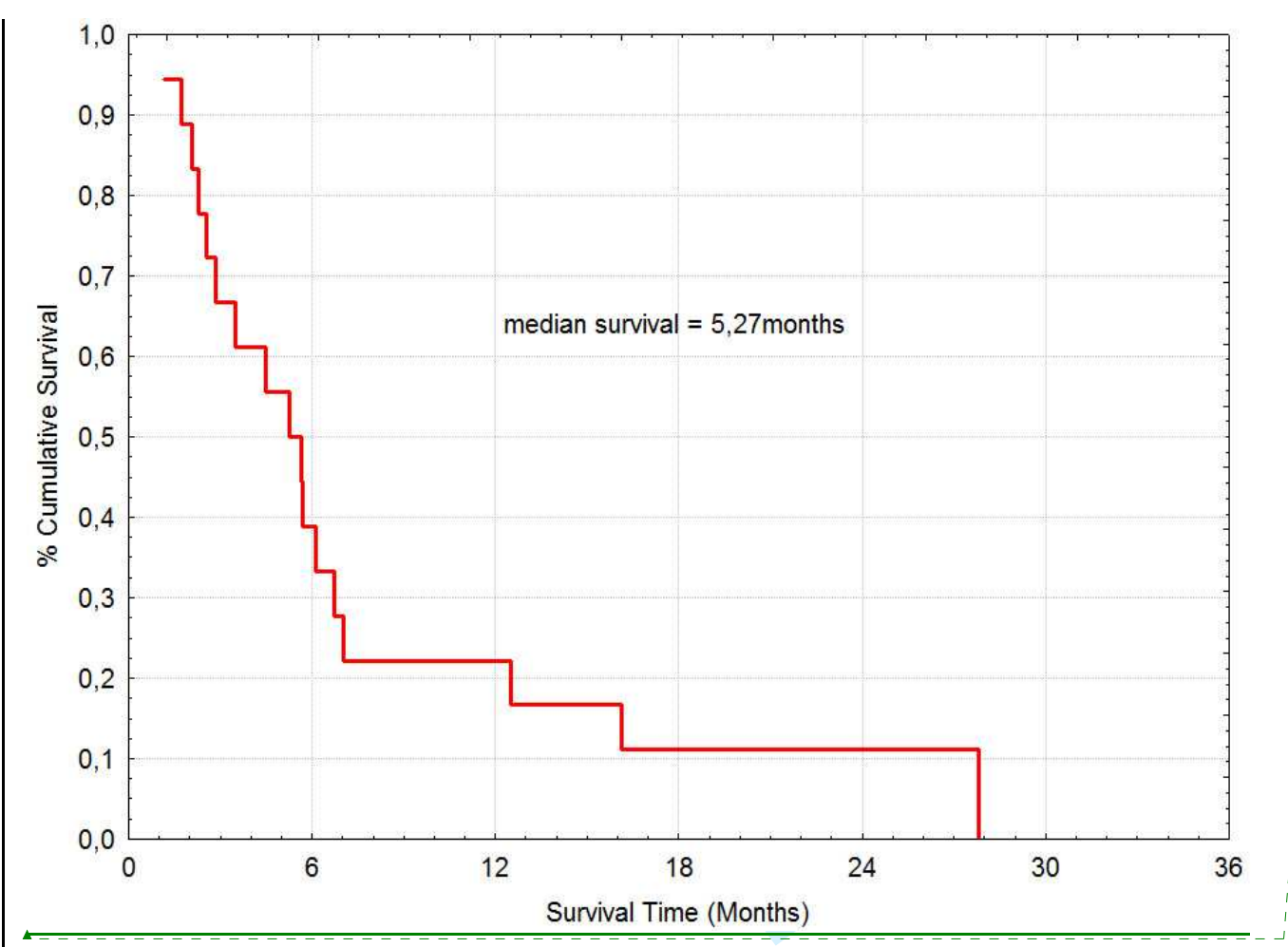

Formatted: English U.S., Do not

check spelling or grammar 
Figure 2

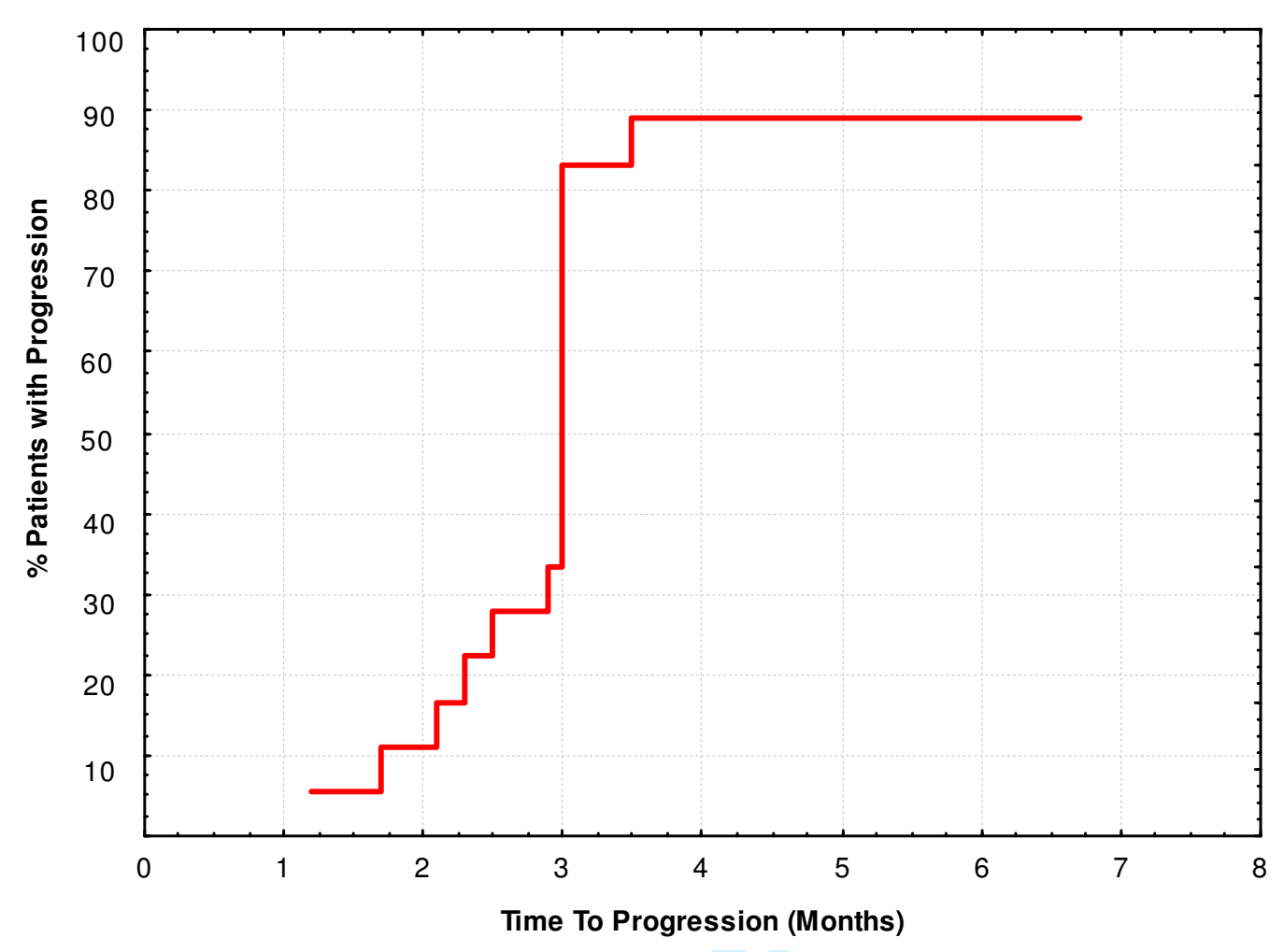


Table 1, Patient characteristics, baseline parameters

\begin{tabular}{|c|c|}
\hline & overall \\
\hline & number (percentage) \\
\hline Number & 18 \\
\hline \multicolumn{2}{|l|}{ Sex } \\
\hline male & $13(72.2 \%)$ \\
\hline female & $5(27.8 \%)$ \\
\hline Median age (range) & $64.2(46.5-80.9)$ \\
\hline \multicolumn{2}{|l|}{ Liver cirrhosis } \\
\hline Child A & $11(61.1 \%)$ \\
\hline Child B & $5(27.8 \%)$ \\
\hline Child C & $2(11.1 \%)$ \\
\hline \multicolumn{2}{|l|}{$\mathrm{BCLC}$} \\
\hline Stage A & 0 \\
\hline Stage B & 2 \\
\hline Stage C & 14 \\
\hline Stage D & 2 \\
\hline \multicolumn{2}{|l|}{ Etiology } \\
\hline alcohol & $9(50.0 \%)$ \\
\hline HCV-antibodies pos. & $5(27.8 \%)$ \\
\hline cryptogen & $1(5.5 \%)$ \\
\hline HBsAg positive & $3(16.7 \%)$ \\
\hline & median ( $\min -\max )$ \\
\hline Creatinin & $0.93(0.69-2.21)$ \\
\hline BUN & $14.0(6.0-69.0)$ \\
\hline Bilirubin & $1.3(0.67-4.53)$ \\
\hline Protein & 73.5 (60.7-92.9) \\
\hline Albumin & $35.2(24.1-52.7)$ \\
\hline Cholinesterase & $3.33(1.00-7.29)$ \\
\hline AP & $186.5(109.0-1018.0)$ \\
\hline AST & $81(41-453)$ \\
\hline ALT & $64(25-192)$ \\
\hline ?GT & $234(61-818)$ \\
\hline CRP & $1.26(0.11-10.78)$ \\
\hline AFP & $163.4(2.70-50,000.00)$ \\
\hline CA 19-9 & $89(1-638)$ \\
\hline Erythrocytes & $4.0(3.1-5.2)$ \\
\hline Haemoglobin & $12.95(10.4-16.1)$ \\
\hline Haematocrit & $38.5(30.6-47.5)$ \\
\hline Thrombocytes & $135(52-511)$ \\
\hline Leucocytes & 7.15 (3.74-10.69) \\
\hline MCV & $92.95(76.70-105.00)$ \\
\hline PT & $74(33-131)$ \\
\hline
\end{tabular}


Table 2, Adverse events/symptoms 
${ }^{1}$ El-Serag HB, Rudolph KL. Hepatocellular carcinoma: epidemiology and molecular carcinogenesis. Gastroenterology. 2007; 132(7):2557-76. Review.

| 2 Llovet J.M., Bru C., Bruix J. Prognosis of hepatocellular carcinoma: the BCLC staging classification. Semin.Liver Dis. 1999; 19: 329-338.

$\mid{ }^{3}$ Giannini EG, Bodini G, Corbo M, Savarino V, Risso D, Di Nolfo MA, Del Poggio $P$, Benvegnù $L$, Farinati F, Zoli M, Borzio F, Caturelli E, Chiaramonte M, Trevisani F; ITALIAN LIVER CANCER (ITA.LI.CA.) GROUP. Impact of evidence-based medicine on the treatment of patients with unresectable hepatocellular carcinoma. Aliment Pharmacol Ther. 2010 Feb 15;31(4):493501. Epub 2009 Nov 14.

${ }^{4}$ Cammà C, Schepis F, Orlando A, Albanese M, Shahied L, Trevisani F, Andreone P, Craxì A, Cottone M. Transarterial chemoembolization for unresectable hepatocellular carcinoma: meta-analysis of randomized controlled trials. Radiology. 2002 Jul;224(1):47-54. Review.

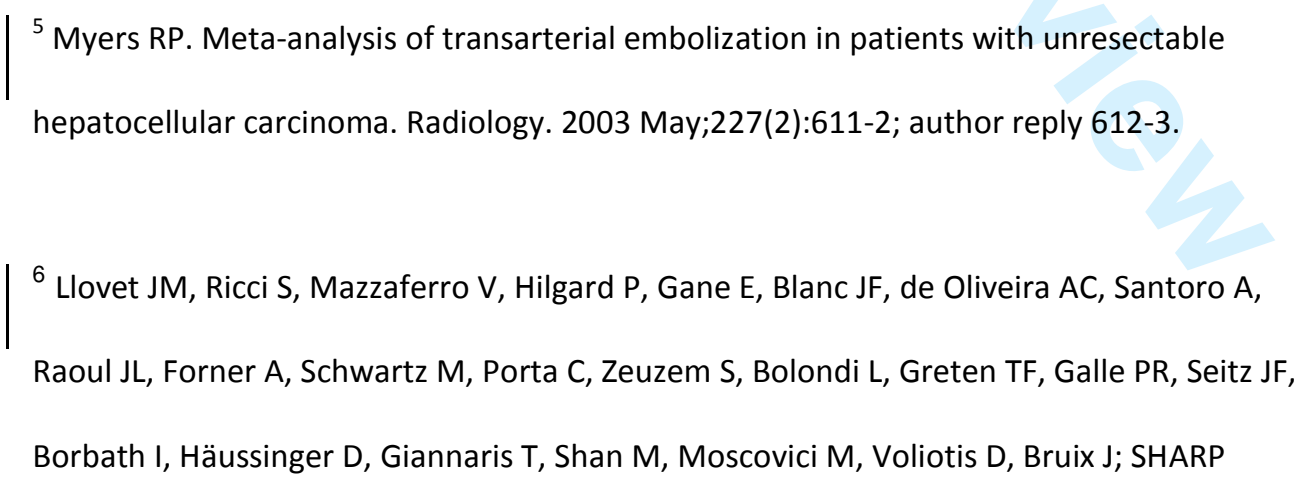
hepatocellular carcinoma. Radiology. 2003 May;227(2):611-2; author reply 612-3. 
${ }^{8}$

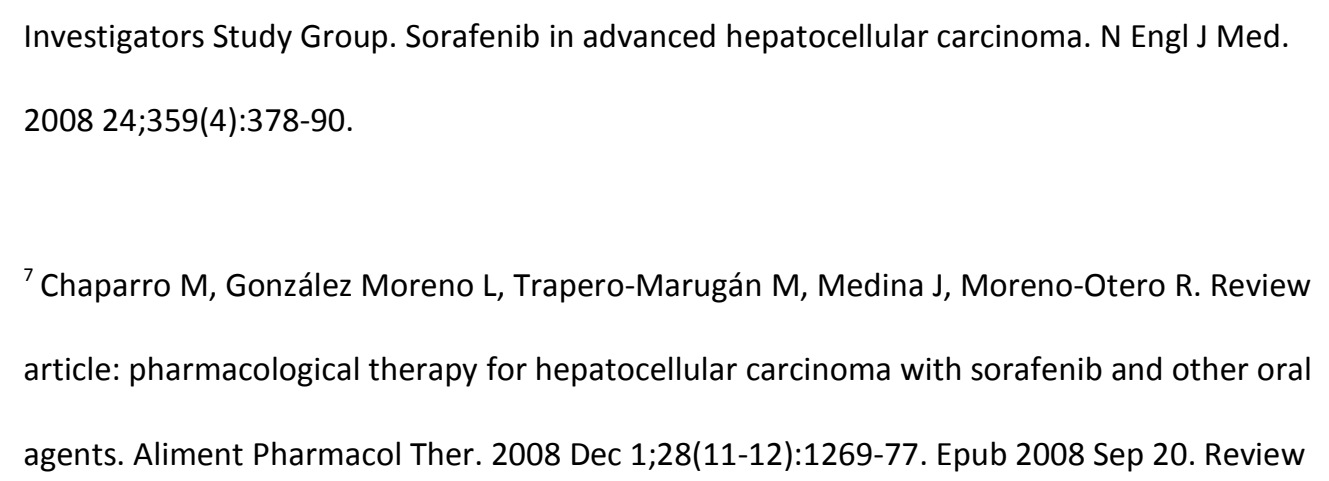
article: pharmacological therapy for hepatocellular carcinoma with sorafenib and other oral agents. Aliment Pharmacol Ther. 2008 Dec 1;28(11-12):1269-77. Epub 2008 Sep 20. Review Aliment Pharmacol Ther. 2010 Feb 15;31(4):461-76. Epub 2009 Nov 19 agents: from bench to clinic. Curr. Opin.Invest.Drugs 2002; 3: 295-304.

${ }^{11}$ Huang S. Houghton P.J. Resistance to rapamycine: a novel anti-cancer drug. Cancer Metastasis Rev. 2001; 20: 69-78.

\footnotetext{
${ }^{12}$ Morelon E., Kreis H. Sirolimus therapy without calcineurin inhibitors: Necker Hospital 5year experience. Transplant Proc. 2003; 35: 52S- 57 S.
} 
${ }^{13}$ Radovancevic B., Vrtovec B. Sirolimus therapy in cardiac transplantation. Transplant Proc. 2003; 35: $171 S-$ !76S.

${ }^{14}$ Trotter J.F. Sirolimus in liver transplantation. Transplant Proc. 2003; 35: 193S - 200S.

${ }^{15}$ Jefferies H.B., Fumagalli S., Dennis B.P., Reinhard C., Pearson R.B., Thomas G. Rapamycin suppresses 5'TOP mRNA translation through inhibition of p70s6k EMBO J. 1997; 16: 36933704.

${ }^{16}$ Terada n:, Patel H.R., Takase K., Kohno K., Nairn A.C., Gelfand E.W. Rapamycin selectively inhibits translation of mRNAs encoding elongation factors and ribosomal proteins.

Proc.Natl.Acad.Sci.USA 1994; 91: 11477-11481.

${ }^{17}$ Villanueva A, Chiang DY, Newell P, Peix J, Thung S, Alsinet C, Tovar V, Roayaie S, Minguez B, Sole M, Battiston C, Van Laarhoven S, Fiel MI, Di Feo A, Hoshida Y, Yea S, Toffanin S, Ramos A, Martignetti JA, Mazzaferro V, Bruix J, Waxman S, Schwartz M, Meyerson M, Friedman SL, Llovet JM. Pivotal role of mTOR signaling in hepatocellular carcinoma. Gastroenterology. 2008 Dec; 135(6):1972-83, 1983.e1-11. Epub 2008 Aug 20.

${ }^{18}$ Newell P, Toffanin S, Villanueva A, Chiang DY, Minguez B, Cabellos L, Savic R, Hoshida Y, Lim KH, Melgar-Lesmes P, Yea S, Peix J, Deniz K, Fiel MI, Thung S, Alsinet C, Tovar V, Mazzaferro V, Bruix J, Roayaie S, Schwartz M, Friedman SL, Llovet JM. Ras pathway activation in hepatocellular carcinoma and anti-tumoral effect of combined sorafenib and rapamycin in vivo. J Hepatol. 2009 Oct;51(4):725-33. Epub 2009 Jun 12 
1

2

3

4

5

6

7

8

9

10

11

12

13

14

15

16

17

18

19

20

21

${ }^{19}$ Bruix J, Sherman M, Llovet JM, Beaugrand M, Lencioni R, Burroughs AK, Christensen E, Pagliaro L, Colombo M, Rodés J; EASL Panel of Experts on HCC. Clinical management of hepatocellular carcinoma. Conclusions of the Barcelona-2000 EASL conference. European Association for the Study of the Liver. J Hepatol. 2001 Sep;35(3):421-30

${ }^{20}$ Bruix J, Sherman M; Practice Guidelines Committee, American Association for the Study of Liver Diseases. Management of hepatocellular carcinoma. Hepatology. 2005 Nov;42(5):120836

${ }^{21}$ Therasse P, Arbuck SG, Eisenhauer EA, Wanders J, Kaplan RS, Rubinstein L et al. (2000) New guidelines to evaluate the response to treatment in solid tumors. European Organization for Research and Treatment of Cancer, National Cancer Institute of the United States, National Cancer Institute of Canada. J Natl Cancer Inst 92: 205-216.

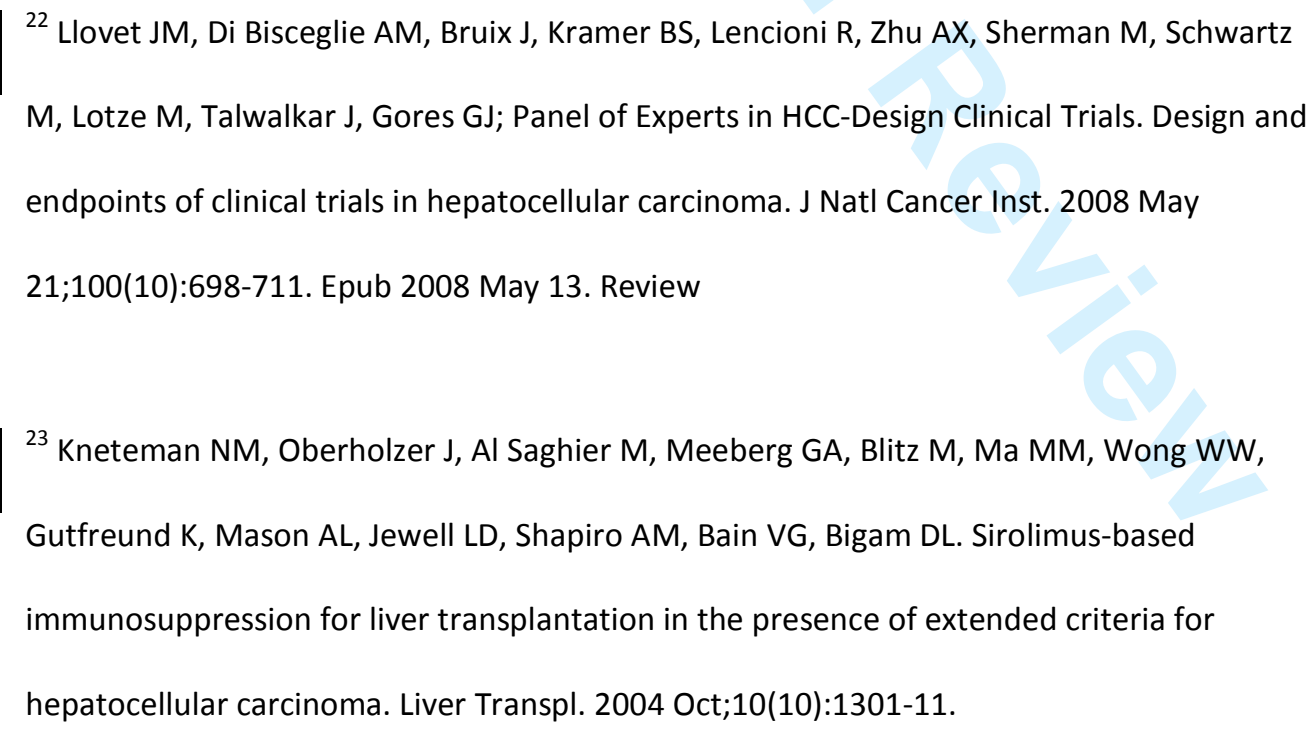


${ }^{24}$ Zhou J, Fan J, Wang Z, Wu ZQ, Qiu SJ, Huang XW, Yu Y, Sun J, Xiao YS, He YF, Wang YQ, Tang ZY. Conversion to sirolimus immunosuppression in liver transplantation recipients with hepatocellular carcinoma: Report of an initial experience. World J Gastroenterol. 2006 May 21;12(19):3114-8.

${ }^{25}$ Elsharkawi M, Staib L, Henne-Bruns D, Mayer J. Complete remission of postransplant lung metastases from hepatocellular carcinoma under therapy with sirolimus and mycophenolate mofetil. Transplantation. 2005 Apr 15;79(7):855-7.

${ }^{26}$ Toso C, Merani S, Bigam DL, Shapiro AM, Kneteman NM. Sirolimus-based immunosuppression is associated with increased survival after liver transplantation for hepatocellular carcinoma. Hepatology. 2010 Apr;51(4):1237-43

${ }^{27}$ Andrassy J, Graeb C, Rentsch M, Jauch KW, Guba M. mTOR inhibition and its effect on cancer in transplantation. Transplantation. 2005 Sep 27;80(1 Suppl):S171-4. Review. 